\title{
CONSIDERAÇÕES SOBRE EXPERIÊNCIAS DO ENSINO DE HISTÓRIA INDÍGENA EM UMA PERSPECTIVA DECOLONIAL
}

\author{
Helena Fediuk Gohl ${ }^{1}$ \\ Cristiani Bereta da Silva²
}

\section{RESUMO}

Este artigo é resultado do Estágio Curricular Supervisionado II e III realizado com a turma 81 na escola Padre Anchieta, em Florianópolis, no ano letivo de 2019. A discussão apresenta a investigação realizada nesse âmbito sobre recepções de estudantes da história indígena por meio de uma pedagogia decolonial, voltada para as narrativas dos próprios sujeitos e suas diversas formas de ser, estar e se colocar no mundo. A temática indígena foi abordada durante três semanas, totalizando nove aulas nas quais priorizou-se a utilização de mídias audiovisuais, reportagens e notícias atuais. Tendo em mente recentes ponderações relativas a implementação da Lei 11.645/2008 analisou-se as atividades propostas e as respostas dos estudantes à metodologia. Nessa direção manteve-se sempre em foco o caráter múltiplo e singular das experiências, o que conduziu a construção de novos caminhos e diversas encruzilhadas.

Palavras-chave: pedagogia decolonial; ensino de História; história indígena.

\section{THE INDIGENOUS BELONG IN THE AMAZON: EXPERIENCES OF INDIGENOUS HISTORY TEACHING IN OTHER PERSPECTIVES}

\begin{abstract}
This article is the result of Practicum II and III courses performed with the 2019 Class \#81 at Padre Anchieta school, in the city of Florianópolis, Brazil. It presents a discussion on the investigation performed about the reception of students to Indigenous History, through a decolonial pedagogy turned to the narratives of subjects and their diverse ways of being, of putting themselves out to the world. The topic of indigenous peoples was approached throughout three weeks, with a total of nine hours of class in which audiovisual media was prioritized, as well as news stories and recent journalism. The proposed activities were analyzed considering recent concerns related to the implementation of Bill 11,645/2008 as well as the students' response to the methodology. The focus was always directed towards the multiple and singular character of each experience, which led to the construction of new pathways and several crossroads.
\end{abstract}

Keywords: de-colonial pedagogy; History teaching; indigenous history.

${ }^{1}$ Graduada em História pela da Universidade do Estado de Santa Catarina (UDESC). E-mail: helenagohl18@gmail.com.

2Professora titular do Departamento de História da Universidade do Estado de Santa Catarina (UDESC). E-mail: cristianibereta@gmail.com. 
Existem nós atados pelas razões ocidentais que nem mesmo ela é capaz de desatar. Assim, o que nos resta na tentativa de desfazer essas amarrações é esculhambálas via os poderes do encante.

Luiz Rufino (2018, p.80)

A proposta desse artigo é discutir, a partir das experiências de Estágio Curricular Supervisionado II e III, realizadas no ano letivo de 2019, as recepções dos estudantes sobre a história indígena por meio de uma pedagogia decolonial. A escolha pela pedagogia decolonial parte de um local de compreensão sobre o sistema educacional brasileiro em sua condição de herdeiro do sistema educacional colonial e seu caráter hegemônico e excludente. Os atuais paradigmas em torno da educação são monoculturais $e$ atendem aos interesses das classes dominantes (LEGRAMANDI; GOMES, 2019). Isto é validado por qualquer procura nos livros didáticos ou nos próprios projetos políticos pedagógicos de grande maioria das escolas brasileiras.

Dentro desta chave de leitura e compreensão, a teoria decolonial se propõe como uma "epistemologia fronteiriça" (MIGNOLO, 2007), focada em construir um "paradigma outro" com conhecimentos diversos, historicamente ignorados ou apropriados pela colonialidade do saber de populações subalternizadas. Neste paradigma o descolamento com as bases epistêmicas ocidentais é essencial para uma educação realmente decolonial e como colocado por Quijano (1992, p.19) em "Colonialidad y Modernidad/Racionalidad":

La crítica del paradigma europeo de la racionalidad/modernidad es indispensable. Más aún, urgente. Pero es dudoso que el camino consista en la negación simple de todas sus categorias; en la disolución de la realidad en el discurso; en la pura negación de la idea y de la perspectiva de totalidad en el conocimiento. Lejos de esto, es necesario desprenderse de las vinculaciones de la racionalidadmodernidad con la colonialidad, en primer término, y en definitiva con todo poder no constituido en la decision libre de gentes libres.

Portanto, a escolha por aulas de história indígena, que permitam que estes sujeitos "falem" por meio dos seus próprios relatos dialoga diretamente com a ideia 
do giro decolonial ${ }^{3}$, explicitado por Luciana Ballestrin (2013) em seu texto "América Latina e o giro decolonial". Apenas por meio de reelaborações e reconsiderações em diálogos contínuos com o que foi comumente considerado "o outro" é que serão possíveis novos caminhos dentro da historiografia e do ensino de História. Walter Mignolo (2007) pontua o papel do Estado como legitimador da criação do outro dentro das Ciências Humanas por meio de conceitos considerados universais como "civilização" e "progresso". Qualquer educação histórica que se proponha "universal" e relega a populações negras e ameríndias como apêndice das aulas e livros didáticos deve compreender seu lugar estrutural na manutenção de uma sociedade hierarquizada e opressiva, que não encara seus próprios impasses.

O trabalho foi realizado num $8^{\circ}$ ano, turma 81 , da escola pública estadual Padre Anchieta, situada no bairro Agronômica, em Florianópolis. O perfil da turma foi investigado pelo grupo de estágio ${ }^{4}$ por meio de questionários. Com base nas respostas dos estudantes observa-se que a turma é composta por uma maioria de estudantes negros $(43.75 \%)$, sendo que $25 \%$ declararam-se brancos. $12.5 \%$ indígenas e $18,75 \%$, outro. Uma estudante se identificou como parda, porém assinalou ter bisavó indígena.

Segundo Quijano (1992, p.93) é necessário pensar a raça como um processo histórico, isso porque a colonialidade é um dos elementos constitutivos do padrão mundial capitalista atual. A dimensão de classe, gênero e raça intersecciona a prática docente e, se a docente for uma mulher branca proveniente de uma família classe média impõem-se desafios relacionados a aproximação e identificação com estudantes, que se reconhecem como negros e indígenas e pertencem às camadas

\footnotetext{
${ }^{3} \mathrm{O}$ termo é cunhado pelo autor Nelson Maldonado-Torres e significa "o movimento de resistência teórico e prático, político e epistemológico, à lógica da modernidade/colonialidade. A decolonialidade aparece, portanto, como o terceiro elemento da modernidade/colonialidade" (BALLESTRIN, 2013, p.105)

${ }^{4}$ Três estudantes formaram um grupo que dividiu os trabalhos nessa turma: Helena Fediuk Gohl; Lara K. Teixeira e Willian Felipe M. Costa. Convém informar que o Estágio Curricular Supervisionado na UDESC ocorre no âmbito de três diferentes disciplinas: I, II e III. As experiências aqui narradas ocorreram nos estágios II e III e abrangeram todo o ano letivo de 2019, na mesma turma.

${ }^{5}$ Questionário aplicado dia 17 de setembro de 2019, situado no início da primeira aula da temática indígena. Algumas ressalvas são necessárias: em razão de ausências de estudantes em sala, as respostas entre os questionários sofrem certa variação.
} 
populares. Outros desafios referem-se a escolha do tema, do problema e da abordagem metodológica relativa ao ensino de História, com o objetivo de aproximar os estudantes desse ensino, para que possam realmente se ver e se reconhecer nos conteúdos para além de um conhecimento abstrato, solto de sua realidade. Como colocado por Fals Borda e Mora-Osejo (2007) por meio da "hipótese de contexto", ${ }^{6}$ é necessário que o conhecimento faça sentido ao estudante, ou seja, esteja "naturalmente" ligado à sua realidade.

Essas foram questões que precisaram ser consideradas na escolha do objetivo e recorte temático: o ensino da história indígena em uma perspectiva decolonial realizado por meio de mídias audiovisuais, imagens, contos e notícias. A ideia foi trabalhar com narrativas produzidas de forma coletivas e/ou individuais pelos próprios indígenas. Primeiro foram mapeadas as concepções prévias dos estudantes sobre a temática, seus olhares e assimilações sobre estas populações. Após o trabalho em sala de aula analisou-se de que forma a metodologia utilizada foi recepcionada e se as percepções iniciais sobre a mesma temática sofreram alguma mudança, após três semanas de aulas em diálogos com indígenas. Diálogos não apenas estabelecidos com a língua escrita, mas principalmente falada, pensando na característica marcante da oralidade, conceito que perpassou transversalmente outra temática trabalhada na mesma turma sobre história africana e afro-brasileira. ${ }^{7}$.

Tendo isto em mente as fontes selecionadas à análise foram de dois questionários $^{8}$, duas atividades escritas ${ }^{9}$ feitas pelos estudantes, assim como suas respostas orais, em sala, registradas nos relatórios semanais individuais. Nesses documentos foram analisadas as categorias mais frequentes nas respostas, suas

\footnotetext{
${ }^{6}$ Trecho presente no texto de Mota Neto. Se refere a "necessidade de adequação dos marcos de referência científicos aos contextos geográficos, culturais e históricos concretos, caso efetivamente se queira enfrentar o colonialismo intelectual e construir uma ciência própria latino-americana" (MOTA NETO, 2019, p.11)

${ }^{7} \mathrm{~A}$ história e culturas africanas, afro-brasileiras e indígenas foi o tema sugerido pelo professor da turma e foi trabalhado durante 8 semanas no estágio III. Antes de se abordar cada tema é exigência da disciplina que sejam mapeadas as ideias prévias da turma. Outra exigência - dentre outras - é que cada estudante escreva um artigo analisando alguma questão recortada da sua experiência de estágio. ${ }^{8} \mathrm{O}$ primeiro questionário foi aplicado no dia 17 de setembro, no início da primeira aula sobre a temática. O segundo foi aplicado dia 01 de outubro, na última semana de aulas de estágio III.

9Sendo estas: uma atividade imagética e uma por meio de relato escrito sobre a mobilidade Guarani. Ambas as atividades serão descritas e analisadas.
} 
características, pensando de que forma os estudantes articulam suas respostas com as aulas dadas e as alterações observadas em suas respostas ao longo do processo. Estes estudantes imaginavam ou idealizavam populações indígenas? Como? Quais conceitos e categorias movimentam para a construção de seu imaginário? A metodologia focada em indivíduos, em suas narrativas e experiências foi produtiva com os estudantes? Notou-se algumas diferenças em suas formas de pensar sobre essas populações após as aulas? O que foi mais ou menos produtivo? Estas são algumas das questões que se pretende abordar neste artigo.

\section{AMARRAÇÕES INICIAIS}

Ao se adentrar na questão indígena em sala de aula não se pode deixar de pontuar historicamente a trajetória de construções e representações sobre essas populações, que permeiam as representações sobre o social. Utiliza-se aqui 0 conceito de representação tal como o abordado por Hall (2016, p.21), que a define como sendo uma ação de "produzir, estruturar e atribuir significados", isto nos leva a pensar a presença indígena dentro da historiografia, assim como na literatura.

Esta presença escassa é, muitas vezes, fortemente marcada por dualismos situados em seus contextos históricos e sociais específicos. São comumente colocados como "selvagens" e "bárbaros' durante todo o processo de chegada europeia. É comum se observar permanências históricas acarretadas por este discurso como argumento de autoridade evocado para a dominação e exploração no período colonial e, posteriormente, para o controle social por meio da tutela durante o governo Vargas em 1930. O currículo de História, como construção social e histórica possui essas marcas de longa duração (SILVA, 2020).

Em outros momentos são romantizados como nos romances de José de Alencar, "O Guarani" (1857) e "Iracema" (1865), alçados a condição de corajosos, puros e ingênuos dentro do ideário do romantismo e da procura pelo herói nacional no pós-independência. Estas representações desembocam atualmente em uma noção generalizante, onde comumente indígenas são vistos de forma difusa como moradores da mata atlântica, preguiçosos, andam nus e sempre de cocar, apenas 
realizando atividades típicas associadas à sua cultura, sem especificação a povos e suas distinções. Diante disto deve-se refletir a qual interesse político está alegoria sobre populações indígenas serve e qual o papel da educação na manutenção, ou desestruturação, de tais estereótipos.

Em conjunto ideias simplistas sobre populações indígenas elas também são constantemente congeladas no tempo na educação histórica, presas ao período colonial e ignoradas na contemporaneidade (MOREIRA, 2013, p.180). Visto que a sala de aula é um local privilegiado e sistemático para construções de significados é pontual a necessidade de uma educação mais crítica e problematizadora, nas quais as nuances históricas de opressão e invisibilização se tornem perceptíveis. De que forma esse ensino fragmentado e ausente reflete na recepção dos estudantes haja vista que, no primeiro questionário aplicado, ${ }^{10} 82.3 \%$ responderam não conhecer nenhuma pessoa indígena e $94.1 \%$ não conheciam nenhuma personalidade de destaque que fosse indígena. $64.7 \%$ colocaram não conhecer nenhuma história ou tradição indígena, apenas $17.6 \%$ conseguiram dar um exemplo e os outros $17,6 \%$ disseram conhecer, mas não lembrar.

Apenas com estes dados pode-se notar que existe uma carência no ensino sobre estas populações, apesar de $88.2 \%$ ter respondido que estudou a temática indígena na escola. Questionou-se "Onde você já ouviu falar sobre indígenas? (Televisão, internet, escola, em casa, etc) "; "O que era falado? ".

Televisão (82.3\%) e escola (76.4\%) foram os principais resultados, seguidos de Internet (29.4\%) e em casa (5.8\%). Na segunda pergunta as respostas mais comuns foram $35.2 \%$ para história, $35.2 \%$ para coisas ligadas a morte e violência, $35.2 \%$ não lembravam, $23.5 \%$ falaram sobre cultura e $5.8 \%$ citou o preconceito. Apesar de a história ter sido um dos temas mais citados, ao ser perguntados sobre o que lembram a maioria esmagadora não sabe ou não lembra de questões relevantes, voltando-se para a questão de opressão, morte e violência. No segundo questionário aplicado ao

\footnotetext{
${ }^{10}$ Este questionário foi aplicado no início da primeira aula sobre a temática indígena (17 de setembro de 2019) e continha perguntas como: Você conhece alguma pessoa indígena? Se sim, quem?; Você conhece alguma personalidade importante indígena? Se sim, qual?
} 
final do estágio, incluiu-se a pergunta "o que você aprendeu na escola sobre os povos indígenas antes das nossas aulas?".

A resposta mais comum foi: Não lembro (44.4\%), seguido por Colonização/povoamento (16.6\%), 5.5\% não respondeu e, Outros (27.7\%) marcado por frases como:

\section{Estudante 1: só falavam que eles moravam na Amazônia}

\section{Estudante 2: aprendi que eles são muito reservados}

Infere-se que apesar de marcarem a opção de já terem tido a temática na escola ela veio de forma esparsa, ou muito breve, pois a maioria da turma não lembra de nada, não respondeu, ou apenas os encaixa no período colonial. Isto demonstra a invisibilidade histórica que a Lei 11.645/2008 vem combater, ela estabelece as diretrizes e bases da educação nacional para incluir no currículo oficial da rede de ensino a obrigatoriedade da temática "História e cultura afro-brasileira e indígena". É sintomática a necessidade de imposição legal para que a temática indígena seja abordada dentro de sala de aula e, mesmo numa investigação com esse recorte (realizada com uma turma, num universo reduzido, portanto) nota-se a influência negativa que um conhecimento fragmentado e estereotipado tem sobre as concepções dos estudantes.

Ao se adentrar na análise das atividades algumas ponderações tornam-se necessárias. Como colocado por Certeau o ato de leitura é amplo e se situa além do livro físico, tendo a oralidade um papel central, ele a situa enquanto parte intrínseca do processo de aprendizagem e apropriação:

[...] somente uma memória cultural adquirida de ouvido, por tradição oral, permite e enriquece aos poucos as estratégias de interrogação semântica cujas expectativas a decifração de um escrito afina, precisa ou corrige. Desde a leitura da criança até a do cientista, ela é precedida e possibilitada pela comunicação oral, inumerável "autoridade" que os textos não citam quase nunca (CERTEAU, 2011, p. 240).

Desta forma podemos situar o ato de assistir vídeos, por exemplo, assim como diversas outras atividades com imagens dentro da lógica de apropriação de leitura abordada por Certeau. Ou seja, como uma operação a qual o leitor ressignifica e 
interpreta o sentido por meio da interação entre a escrita e a herança oral e histórica. Portanto, na segunda atividade realizada em duplas, os estudantes deveriam olhar para diversas imagens de pessoas indígenas e assinalar quais viam como "mais" ou "menos" indígenas e justificar uma de suas escolhas. Obviamente a proposta é uma pesquisa prévia direcionada, porém o interesse recaía sobre as justificativas.

A escolha das imagens foi dividida entre atividades consideradas "tipicamente" indígenas e em pessoas indígenas realizando outras atividades não comumente associadas a estas populações como presença na política, no rap, na cidade e na produção cinematográfica.

Estudantes 1 e 2: representa menos porque o jeito de se vestir deles é diferente, o corte de cabelo e as tatuagens e também porque eles moram na cidade.

Estudantes 3 e 4: porque não mostra a cultura dele e por parecer uma pessoa normal.

E os estudantes 5 e 6 deram uma das respostas mais pontuais: da mulher com camiseta e tatuagem e cabelo em paisagem de prédios, porque não tem nada a ver com o indígena e ela está atrás de prédios, o lugar de indígena é na mata amazônia [...]

Os estudantes ao colocarem que o "lugar de indígena é na mata amazônica" refletem um lugar de fala específico, relacionado com a herança colonial, opressora. Lugar que delimita o território a partir da hierarquização do acesso que certas populações podem ou não ter, ignorando as organizações posteriores e a permanências históricas das populações indígenas no território brasileiro. Esta posição também evidencia o paradoxo de uma sociedade que muitas vezes exige aos indígenas que estejam em matas e locais isolados para serem validados, ao mesmo tempo que age coletivamente atingindo seus locais de sobrevivências para continuar a produção exaustiva da agropecuária e do agronegócio.

Oito das nove atividades apontaram Katú Mirim ${ }^{11}$ como a que menos representaria o "ser" indígena. Ela foi seguida por quatro para Sônia Guajajara12

\footnotetext{
${ }^{11}$ Rapper e indígena urbana da etnia Boe Bororo, conhecida por suas letras de resistência e existência. ${ }^{12}$ Sônia é do povo Guajajara/Tentehar, que habita as matas da Terra Indígena Araribo. É uma importante liderança indígena no contexto atual e a primeira mulher indígena a compor uma chapa para disputar a Presidência da República.
} 
discursando no Senado, quatro para o indígena utilizando uma câmera de cinema e três para o Kunumi $\mathrm{Mc}^{13}$. Todas estas escolhas exprimem o consenso não dito sobre o local dado aos indígenas no imaginário social, isto resulta em diversas práticas violentas verbais, físicas ou simbólicas. Um grupo ao colocar Sônia como menos representativa argumenta "porque um índio nunca foi prefeito". Esse grupo faz uma associação entre a ausência indígena na política e o fato de que essa população seria menos indígena quando se encontra nessa posição. Portanto, esta mesma ausência e falta de acesso a estes locais alimentam ideias limitantes no meio social.

Outra resposta pontual foi sobre o indígena gravando a aldeia: "menos representa porque ao invés de estar com o grupo ele está gravando". Aqui nota-se que essas mesmas estudantes marcaram no questionário como falso o fato de que utilizar a tecnologia os faria menos indígenas. Contudo, como se observa este ainda era um conhecimento novo para a turma, portanto durante a aula foram utilizados dois vídeos: o primeiro do youtuber indígena Guarani, o Wariu: "O que é ser indígena no século XXI. EP.1"14 e o segundo "ISA - \#MenosPreconceitoMaisÍndio"15, produzido pelo Instituto Socioambiental para discutir o uso da tecnologia e as inovadoras formas de lutas indígenas por meio de redes sociais que vem estabelecendo novos vínculos e sociabilidades, aproximando-os.

As inovações tecnológicas dos últimos anos reconfiguraram o jogo político, pois os modelos de representações políticas se encontram em constante movimento, ampliando e, assim, democratizando, acessos, ainda que limitadamente. Este contexto toca as populações indígenas de variadas formas, sendo um deles as formas de atuação e militância política que se constitui nas redes por meio de youtubers indígenas e sites como a Rádio Yandê ${ }^{16}$ e Vídeo nas Aldeias ${ }^{17}$, voltadas para a

\footnotetext{
${ }^{13}$ Werá Jeguaka Mirim, rapper Guarani residente da aldeia de Krukutu, na região de Parelheiros, na zona sul de São Paulo. Ficou conhecido por seu ativismo e letras voltadas para luta de demarcação de terras.

${ }^{14}$ Disponível em: <https://www.youtube.com/watch?v=XDaS70F2fPw>. Acesso: 24 nov. 2019

${ }^{15}$ Disponível em: $<$ https://www.youtube.com/watch?v=uuzTSTmlaUc $>$. Acesso: 24 nov. 2019.

${ }^{16}$ Rádio Yandê: "Comunicação e Etnomídia Indígena". Para mais informações, ver em:<http://radioyande.com/> Acesso : 19 nov. 2019.

${ }^{17}$ Vídeo nas Aldeias: "Precursor na produção audiovisual indígena". Para mais informações, ver em: <http://videonasaldeias.org.br/loja/> Acesso: 19 nov. 2019.
} 
produção e divulgação de conteúdo como notícias, músicas e filmes. Os vídeos utilizados, portanto, se encaixam neste contexto e dialogam com a contemporaneidade que tentamos demonstrar aos nossos estudantes, retirando a ideia de indígena congelado no tempo.

Já as imagens escolhidas como mais representativas foram: nove para danças típicas, cinco para o homem do povo Pataxó com o arco e flecha, quatro para Sônia Guajajara e dois para o Kunumi Mc. As respostas que validaram suas escolhas eram:

Achamos que é mais porque ele está fazendo algo que é de seu povo. (sobre a imagem do indígena Pataxó com o arco e flecha)

Representa mais porque eles se juntam em uma roda, dançam, cantam, faz pinturas no corpo e tradições etc.

Nota-se, aqui, que as noções limitantes e generalizantes propagadas sobre populações indígenas reverberam nos estudantes, que acreditam que apenas se é indígena ao se representar uma caricatura do "dia do índio". Foi, portanto, nesta linha que a aula e o debate seguiram, evidenciando aos estudantes a luta indígena em diversos espaços, assim como a diversidade de modos de ser e estar no mundo como pessoa indígena por meio de personalidades importantes no contexto brasileiro atual, já citadas anteriormente. Observa-se a atividade como positiva, pois diversos estudantes, ao verem os vídeos e notarem o racismo em suas próprias respostas, compreenderam com um pouco mais de facilidade os problemas advindos de certas concepções.

No relatório semanal individual há comentários sobre as diversas reações dos estudantes ${ }^{18}$. Por exemplo, uma estudante nova na turma, vinda do Piauí, que se identificou como indígena, aparentou estar emocionada e outros estudantes, que antes faziam piadinhas sobre a Katú "parecer uma cheiradora", ao verem Wariu falando sobre seu povo e seus direitos, se tornaram mais compassivos e não se ouviu

\footnotetext{
${ }^{18}$ Este relatório, de Helena F. Gohl, refere-se a aula ministrada em 17 de setembro de 2019. Segue o trecho citado: "Um dos momentos mais interessantes foi a reação dos alunos ao passarmos o vídeo do youtuber Wariu. Ao verem Wariu falando notei, pelo menos a partir do meu ponto de vista, mudanças em suas expressões e comentários, não era mais um indígena imaginário de quem estávamos falando, mas sim pessoas reais com demandas e lutas reais. Alunos que antes riram e zombaram das imagens após a discussão com os dois vídeos não o faziam mais. [...]"
} 
mais piadas. Estas populações sofreram com o processo de desumanização e simplificação de sua existência, portanto é de extrema importância levar suas narrativas para dentro da sala de aula. Os estudantes precisam ver que estas pessoas são reais e existem e resistem em diversos espaços para que a ideia mítica e idealizada de que a populações indígenas residem num passado longínquo dê lugar a compreensão de que fazem parte do presente, residem no Brasil inteiro e nos sãos próximos. E, o mais importante, o fato de a luta indígena ser a luta de todos.

Ao se notar que os principais tópicos que lembram os estudantes sobre os povos indígenas envolvem os ataques e as opressões sofridas, como evidenciado antes, deve-se manter em mente que, obviamente é de extrema importância que a realidade passada, e atual, de ataques a aldeias indígenas seja frisada e visibilizada. Contudo, importa se ater também em fixar esta exposição a realidade histórica de opressão, assim como à luta secular de resistência indígena, para que esta violência não fique deslocada do tempo e do espaço ou recaia em uma mentalidade onde estes povos são apenas sujeitos vítimas sem possibilidade de agência. Esta luta tem importância emergencial abrangendo outras áreas como a atual situação ambiental no Brasil e o ataque constante de madeireiros, mineradores, garimpeiros, grileiros etc., às comunidades e aldeias indígenas por questões de terra. Diante disto uma questão impera: a quem serve o apagamento da história indígena?

\section{DESATANDO OS NÓS}

A história indígena é abrangente e reúne conhecimentos de variadas áreas, questionando até mesmo os moldes educacionais ocidentais e propondo novos paradigmas para uma educação mais significativa para o estudante. Pensando nisso tentaram-se metodologias como jogos de peteca no pátio da escola. Os estudantes mostravam-se muito animados para atividades fora da sala de aula, porém neste dia se tratava da primeira aula da manhã e muitos não quiseram participar, provavelmente por diversos motivos ligados a timidez e também um pouco de preguiça de sair de seu lugar de conforto, de expectador. 
Dinamizar as aulas traz empecilhos devido à comodidade do padrão educacional atual, o qual, nas palavras dos próprios estudantes "eles apenas sentam e escutam". Como não estão acostumados a serem protagonista, ou não se veem como sujeitos ativos no processo de produção do conhecimento, propostas mais ativas, por vezes, encontraram certa resistência, assim como propostas que alterem o "comum", como sentar em roda ou falar em frente a turma.

No desenvolvimento da pesquisa de William Costa, outro membro grupo que trabalhou na mesma perspectiva com a história africana e afro-brasileira, planejou-se aulas como uma caça ao tesouro, saída de campo e jogos de verdadeiro ou falso. Estas experiências se destacaram pela recepção positiva de maioria dos estudantes, já outros viam a maior dinamização como uma "chatice" nossa. Isto possui variados motivos, desde questões pessoais desconhecidas até a timidez de falar em frente a turma ou a preguiça de ter que agir efetivamente, saindo apenas do local de ouvinte.

O período de estágio é limitado, não é possível ficar todo o ano letivo como "docente" de uma mesma turma, diante disso não foi mesmo possível romper totalmente com essa espera dos estudantes, mas notou-se diferenças significativas em relação a sua reação a aulas diferenciadas em contraposição a aulas mais expositivas, assim como à sua aceitação a novas abordagens.

A escolha por uma metodologia mais visual ao longo do projeto de estágio baseou-se na compreensão de que uma educação ampliada com músicas e vídeos é capaz de facilitar a aprendizagem. Segundo Ferrés (1996, p.25) se o método de ensino for oral e visual conjuntamente os estudantes conseguem reter $85 \%$ dos dados após 3 horas e 65\% após 3 dias, em contraste com o método apenas oral onde os números caem para $70 \%$ e $10 \%$ respectivamente. Os dados refletem no questionário final, ao serem perguntados "dos materiais que trabalhamos em sala de qual você mais lembra ou mais gostou de ver? ", $61.1 \%$ respondeu vídeos, $27.7 \%$ responderam músicas e imagens e apenas 5.5\% ressaltou ter gostado de trabalhar com textos. Durante as observações iniciais, nas aulas do professor Márcio Lacerda, a turma sempre gostou de vídeos e prestavam atenção, portanto decidiu-se que, no estágio, 
se trabalharia com vídeos curtos, de no máximo cinco minutos, e fazer perguntas aos estudantes logo em seguida, dinamizando a aula.

Estes dados nos propiciam um panorama diante da atividade realizada com textos $^{19}$. Notou-se mais dificuldade por parte dos estudantes, principalmente em momentos em que se exigia interpretação mais sistemática. Isto pode ter diversas causas como o pouco hábito de leitura, certa comodidade em respostas prontas, ou falta de familiaridade com o diálogo em sala entre estudantes e educador. Esta realidade reflete nas respostas desta atividade: de 15 alunos, seis copiaram frases inteiras do texto ou das notas de rodapé como a resposta sem interpretar o que estava sendo pedido, outros estudantes acertaram as questões, mas deixaram algumas incompletas. Portanto classificou-se como uma "boa" apropriação estudantes que acertaram a maioria das questões de forma considerável, articulando o que foi pedido com o texto e a explicação em sala, cerca de 53.33\%. Para uma apropriação média $26.6 \%$ dos estudantes compreendeu algumas questões e não outras como, por exemplo, o papel de Nhanderu enquanto guia do Belo Caminhar, mas não a divisão de fronteiras na concepção Guarani. Outros 26.6\% tiveram uma apropriação frágil do conteúdo, pois apenas copiaram trechos do texto e responderam todas as questões de forma superficial.

Já o debate com os vídeos foi proveitoso e pareceu exemplificar aos estudantes as questões discutidas como a noção de fronteiras para os Guaranis, a luta pela demarcação de terras, os motivos do Belo Caminhar e a ligação inerente entre estes pontos e a cosmogonia Guarani. O trecho do filme na aula seguinte, "Bicicletas de Nhanderu" (38:07 - 40:17), foi um dos mais citados pelos estudantes posteriormente. Ele foi utilizado para exemplificar as diferenças entre uma escola no meio urbano e uma escola em uma aldeia Guarani ${ }^{20}$, o objetivo era oportunizar que os estudantes compreendessem que o modo de aprender indígena vai além dos muros da escola.

\footnotetext{
${ }^{19}$ Nesta aula utilizamos inicialmente o texto curto "relato de Xejaryi Tereza - Djatxuca, relato de mobilidade Guarani sobre Belo Caminhar", com quatro perguntas a serem respondidas e a frase de Casé Angatu Xukuru Tupinambá: "Nós não somos donos da terra, nós somos a terra", complementamos a discussão posteriormente com trechos de filmes, sendo estes: "Duas aldeias, uma caminhada" e "Guataha".

${ }^{20}$ Manter sempre em mente as realidades distintas entre aldeias, evitando generalizações.
} 
Ao mostrar o menino entediado em sala e sua liberdade em poder sair a qualquer momento para construir a Casa de Reza, se quis que os estudantes notassem a parte prática do processo de aprendizagem e a existência de diferentes caminhos e possibilidades dentro da educação. Amarrou-se isto com um vídeo de contação de história Guarani, "O Roubo do Fogo" notando a forma em que descobrimento do fogo é narrado e sua relação com a natureza, refletindo sobre a oralidade e a aprendizagem indígena.

Nas palavras de Luiz Rufino (2018, p.87): "a racionalidade moderna ocidental é decapitada e assombrada pela má sorte de ter o corpo (bara) deslocado da cabeça (ori)" (grifo nosso). A escola ocidental espera a obediência, o silêncio e o imobilismo pois se posiciona como "lógica", "mental", tenta ignorar a pulsação do corpo. Reparte o conhecimento e o compartimentaliza (CASTRO-GÓMEZ, 2007), mas não basta apenas um olhar para dentro das salas de aula para notar que o corpo não se permite ser cativo? As crianças vibram, palpitam dentro de si e entre os outros em suas constituições em sua condição de seres viventes e os questionamentos sobre educação transversalizam o corpo em todas as suas esferas. É por meio dele que lemos, vemos, ouvimos, tocamos e trocamos saberes, portanto notar que o corpo estudantil é aprisionado no atual espaço escolar é uma das posições educacionais indígenas que se tentou ressaltar.

O corpo separado da mente e a escola afastada da vida, e as crianças aprendem sem saber que o fazem nas ruas, com os colegas, nas mídias e redes sociais e principalmente, com e para seu corpo. Corpo este que é silenciado e controlado na entrada do colégio e colocado na modernidade/colonialidade apenas como representação física do ser, terreno fértil para projeção de desejos e criação de vínculos mercadológicos por parte do capitalismo. O paradigma decolonial pontua que outras lógicas são possíveis, seja ela no movimento do feminismo negro ou na vivência Guarani, elas são múltiplas e diversas. O corpo vai muito além de uma representação ou um instrumento de apropriação, ele é memória viva, carrega ancestralidade e pertencimento, está no centro do processo de reconhecimento do eu enquanto sujeito histórico (ANTONACCI, 2013). A procura por novos sentir, novos 
caminhos decoloniais envolve a re-compreensão do corpo como relação, como corpomundo, não apenas individualidade, mas sim comunidade e coletividade. É este corpo em sala de aula que experiência a violência, o racismo, não outro além, distante. Ele é espaço fronteiriço onde se encontram memórias e sociabilidades, desencontros e reconexões, é a este corpo que é ditado os locais aos quais ele pode ou não circular e como ele pode ou não agir em determinadas situações.

Este reconhecimento é essencial para professores e estudantes, mas é indiscutivelmente desafiador no modelo educacional atual. É desafiador também internamente, pois somos criados neste sistema e estamos confortáveis em aulas expositivas e apresentações de slides. Quebrá-lo implica em dobrar-se sobre si mesmo várias vezes, implica em aprendermos a lidar com o movimento em nossos estudantes e em nós mesmos. De uma perspectiva crítica sobre a própria atuação do grupo não se avalia que isto foi algo alcançado em três semanas, pensa-se que o objetivo pretendido está em construção e será posteriormente delineado nas práticas docentes de cada membro do grupo. O estágio foi importante para a percepção, na prática, de que se deve ouvir nossos estudantes, e o corpo fala.

Propôs-se então a análise das fontes finais sobre a recepção dos estudantes do conteúdo, assim como ponderações sobre a metodologia. No questionário final incluíram-se questões com o intuito de investigar o que foi apropriado pelos estudantes de questões centrais passadas como suas lutas atuais e presença nas cidades e, por fim: "Você mudou sua maneira de pensar sobre as populações indígenas após nossas aulas? O que mudou? ". Inicia-se por este dado pois se considera relevante e positivo. $72.2 \%$ responderam sim, contra $27.7 \%$ não. Algumas respostas se destacam por demonstrarem a desnaturalização de convicções racistas como em:

Sim, porque achava que eles eram preguiçosos, mas não são;

Fiquei sabendo que eles não são porcos;

Eu achei que eles só viviam escondido e tal, mas não.

Notável que ao perguntar, no segundo questionário, se já haviam ouvido comentários preconceituosos sobre indígenas $72.2 \%$ responderam não, contra $22.2 \%$ sim. Haja vista que os próprios estudantes expressaram comentários ou 
posicionamentos preconceituosos durante as aulas, pode-se pensar que o conceito ainda é difuso aos estudantes e talvez não ocorra a identificação de ações racismo velado, apresentadas como apenas "opiniões sinceras". Outras respostas demonstram uma compreensão da atualidade da discussão e de uma luta por direitos:

Porque a gente aprende a valorizar mais as pessoas e as lutas do dia a dia.

Sim, o direito dos índios sobre o território.

Sim. Agora eu sei que eles são pessoas que só querem o que pertence a eles.

Os conflitos por terras foram um dos eixos centrais das discussões posto a indissociabilidade deste tema ao modo de vida indígena. Na questão "Quais as principais lutas indígenas atualmente? ", $88.8 \%$ mencionaram terras, $22.2 \%$ direitos de forma ampla, $11.1 \%$ citaram o direito à cultura, e à natureza $5.5 \%$. Em relação a conhecer alguma tradição ou História indígena os dados sofrem mudanças: $38.8 \%$ conseguiu responder algum exemplo, contra $17.6 \%$ anteriormente. Em três semanas os resultados são modestos, não ocorreram mudanças drásticas e com certeza diversos estudantes não foram alcançados pela temática de forma totalmente satisfatória, mas o Quiz final também vale ser ressaltado, pois todos os grupos foram muito bem em suas respostas, ficando uma vitória apertada de um ponto entre um e outro.

No geral, considerando o tempo de aulas dedicadas à história indígena especificamente, observa-se o resultado dos estudantes como produtivo. Orientar as aulas por meio de narrativas próprias, principalmente audiovisuais, foi uma escolha importante no processo de criação de afetividade e aproximação com o conteúdo, principalmente notando o pouco contato anterior dos estudantes com populações indígenas e os muros levantados nesta socialização pelas construções sociais existentes.

\section{LAÇOS, OU CONCLUSÕES}

Se o experimento é genérico, a experiência é singular. Se a lógica do experimento produz acordo, consenso ou homogeneidade entre os sujeitos, a lógica da experiência produz diferença, heterogeneidade e 
A experiência em Estágio Curricular Supervisionado foi elucidativa e pavimentou um caminho, na teoria e em prática, para a atuação profissional futura, um caminho de muitos, nos quais espera-se seguir as encruzilhadas de experiências (RUFINO, 2018). Elas apenas são possíveis se permitimos vivências e narrativas outras dentro das salas de aula, portanto não se deve encarar o processo de descolonização como um ponto de desfecho, mas sim como a alvorada de muitas dúvidas, pois nas palavras de Rufino: "nos resta lançar nossos dilemas na encruza, rasurá-los e reescrevê-los de forma cruzada" (RUFINO, 2018, p.79). No entremeio entre culturas, vidas e experiências não existem certezas, apenas trocas e vivências múltiplas que, ao se encontrarem criam por vezes nós, por vezes laços. Portanto, este artigo não se pretende certeza ou resolução, mas sim trajetória, experiência, possibilidade. Desataram-se alguns nós, encontraram-se diversos outros e escolheram-se alguns caminhos.

A escolha de um posicionamento na prática docente, por meio de uma pedagogia decolonial, é, além de teórica, prática e política. Bondía (2002) ressalta a urgente necessidade de nos voltarmos para a experiência, voltar-se para a experiência é voltar-se para o corpo, e voltar-se para o corpo é quebrar com a separação ocidental, racional e moderna onde andamos decapitados de nós mesmos. A dificuldade evidente de se criar, para além de aulas expositivas, não está desligada da construção colonial que nos envolve até a medula e portanto, o recriar é diário. Quebrar com estes padrões é trabalhoso, cansativo, pois nada contra a corrente e muitas vezes se depara com uma falta de exemplos práticos, seja na vida ou na universidade. Mensurar o resultado objetivo das aulas é difícil e a experiência serviu como uma lupa para diversas direções no processo de constituição pessoal e profissional, como docente. Se por um lado comprovou-se a necessidade emergencial de uma educação libertadora e decolonial em prática, também saio com muitas possibilidades e incertezas.

Ressalta-se como positivo que a metodologia escolhida permitiu diálogos com as populações indígenas, evidentemente há ressalvas, mas elas devem-se a natureza 
da prática docente numa situação de estágio. Da experiência fica a lição de tentar realmente encantar os estudantes com possibilidades, mesmo que difíceis, de uma educação diferente, de um modo de ser, estar e se posicionar no mundo que é outro e diverso. Mesmo se não se conseguir revolucionar todos os dias na prática diante dos imensos e variados desafios materiais e sociais, estas possibilidades existem e nossos estudantes merecem saber. Portanto, nota-se como de extrema importância que os espaços que possam ser ocupados pelas narrativas destes sujeitos sejam evidenciados e ressaltados. As possibilidades de uma pedagogia decolonial estão em ampliar os horizontes para além da educação histórica hegemônica e utilizar-se de diversos métodos para levar isto em sala. Audiovisuais, contos e jogos, foram recursos aliados para a metodologia proposta nessa turma.

No geral essa vivência proporcionou contato direto com o público educacional e uma melhor compreensão do contexto escolar brasileiro, desde Florianópolis, assim como possibilitou uma aproximação com o grupo de trabalho durante 0 desenvolvimento do projeto de estágio docente, pensado e realizado de modo colaborativo, desde o planejamento das aulas até a sua efetivação. Isso mostra que o trabalho coletivo não é apenas possível, como muito benéfico para a produção de conhecimento quando realizado com responsabilidade por todos os envolvidos.

\section{REFERÊNCIAS}

ANTONACCI, Maria Antonieta. Memórias ancoradas em corpos negros. São Paulo: EDUC - Editora PUC-SP, 2013.

AMORIM, Roseane; SILVA, Cintia. O uso das imagens no ensino de História: reflexão sobre o uso e a interpretação das imagens dos povos indígenas. História \& Ensino, v. 22, n. 2, p. 165-187, jul/dez. 2016

CASTRO-GÓMEZ, Santiago. Decolonizar la Universidad: La hybris del punto cero y el diálogo de saberes. In: CASTRO-GOMEZ, Santiago; GOSFROGUEL, Ramón. EI giro decolonial: reflexiones para una diversidad epistémica más allá del capitalismo global. 21 ed. Bogotá: Universidad Javeriana-Instituto Pensar, Universidad CentralIESCO, Siglo del Hombre, 2007, p. 79-91. 
CERTEAU, Michel de. "Introdução geral"; "Ler: uma operação de caça". In: invenção do cotidiano. Tradução de Ephraim Ferreira Alves. 17ª ed. Petrópolis, Rio de Janeiro: Vozes, 2011, pp. 37-51; 236-248.

BALLESTRIN, Luciana. América Latina e o giro decolonial. Rev. Bras. Ciênc. Polít., Brasília, n. 11, p. 89-117, ago. 2013.

BONDÍA, Larrosa Jorge. Notas sobre a experiência e o saber da experiência. Revista Brasileira da Educação. № 19, p.20-28, jan/fev/mar/abr. 2002.

FERRÉS, Joan. Vídeo e Educação. 2ª Ed., Porto Alegre. Artes Médicas, 1996a.

HALL, Stuart. Cultura e Representação. Rio de Janeiro: Apicuri, 2016. 260 p.

LEGRAMANDI, A.B; GOMES, M.T. "Insurgência e resistência no pensamento freiriano: propostas para uma pedagogia decolonial e uma educação emancipatória". Revista Ambiente e Educação. São Paulo, USP, v.12, n.1, pp.24-32, 2009

MARIANO, N. R. C. A representação sobre os índios nos livros didáticos de História do Brasil. 2006. 109 fls. Dissertação (Mestrado) - Universidade Federal da Paraíba, João Pessoa, 2006.

MIGNOLO, Walter D. Desobediência epistêmica: a opção descolonial e o significado de identidade em política. Revista Gragoatá, n. 22, p. 11-41, 1ํ sem. 2007.

MOREIRA, Maria Geralda de Almeida. Entre silêncios e representações: história e cultura indígena no ambiente escolar. Revista Polyphonía, v. 24/1, p. 176-188, jan./jun. 2013.

MOTA NETO, João Colares da. Por uma pedagogia decolonial na América Latina: Convergências entre a educação popular e a investigação-ação participativa. Arquivos Analíticos de Políticas Educativas, Pará, v. 26, ed. 84, p. 1-21, 23 jul. 2019.

RUFINO, Luiz. Pedagogia das Encruzilhadas. Revista Periferia, v.10, n.1, p.71-88. Jan./Jun. 2018.

SILVA, Cristiani Bereta da. Ensinar História: práticas culturais e políticas nos tempos dos exames de admissão ao Ginásio (1931-1971). Rio de Janeiro: Mauad X, 2020.

SOUZA, Josiane Nazaré Peçanha de. Por uma educação transgressora: antirracista e decolonial. KWANISSA - Revista de Estudos Africanos e Afro-Brasileiros, n. 3, p. 115-131, jan/jun, 2018.

QUIJANO, Aníbal. Colonialidad del poder y clasificación social. In: BONILLO, Heraclio. Los conquistados. Bogotá: Tercer Mundo Ediciones; FLACSO, 1992, p.437-449. 
Criar Educação, Criciúma, v. 10, ํo1, jan/jul 2021 - PPGE - UNESC - ISSN 2317-2452

Recebido setembro de 2020

Aprovado abril de 2021 